\title{
Title: Identifying the categories of spiritual experience encountered by therapists in
} their clinical work

\author{
Alistair Ross \\ Director of Psychodynamic Studies, University of Oxford \\ alistair.ross@conted.ox.ac.uk
}

\begin{abstract}
Spirituality has replaced religion in popular culture and its presence is being felt in the therapeutic world. Using a questionnaire completed by 104 people utilizing 6 descriptive definitions of spirituality and 36 categories of spiritual experience, three meta-themes of forms of spirituality emerged through a thematic analysis. These are spiritualties of the Sacred, the Self and the Senses. When the therapist's theoretical orientation is identified there are different expressions of the spirituality that emerges. Of specific importance is that due to approximately $90 \%$ of the respondents being female what emerges therefore is an expression of female spirituality. More research will be required to identify if there is matching male spirituality.
\end{abstract}

\section{Keywords}

Spirituality; spiritual experiences; quantitative methodology; Self; Sacred; gender; theoretical orientation

\section{Introduction}

Following a life-threatening fall while climbing in Snowdonia in early 2014 resulting in seven fractures to both ankles and my right wrist I was unable to work as a therapist for six months. While I have written about this elsewhere (Ross 2014) the impact remains. One client on returning to our therapeutic work said 'I found myself praying for you, which is kind of weird as I don't even believe in God'. I was touched by their concern and intrigued by their expression using spiritual terms, perhaps knowing that I had a religious background and wanting to communicate with me in a different, a-therapeutic way? For this they found the language of religion and the practice of prayer as a form of spirituality. As I listen to therapists from a wide range of backgrounds with or without any form of religious or spiritual 
commitment I hear many such similar reports of a 'spiritual' expression taking place within therapy. These experiences motivated me to return to some unpublished research I had conducted between 2006 and 2012 seeking to investigate what might be going on.

The first factor that emerges in the literature is the growing distinction between religion and spirituality in Western culture. There is a widespread misunderstanding as to what religion and spirituality are seen in the instinctive emotive response: spirituality $=$ good, religion $=$ bad (Ross 2006). This view has become more entrenched, influenced by the surge of fundamentalism that is assaulting our Western worldview. Taking a broad and inclusive approach religion can be viewed as,

an organised system of beliefs, practices, rituals and symbols that can be seen to be designed to (a) facilitate closeness to the sacred or transcendent being (God, higher power or ultimate truth/reality) and (b) foster an understanding of one's relationship and responsibility to others in living together in a community (Candy et.al 2012: 2).

By contrast the term spirituality although linked to religion historically has in contemporary culture expanded to include non-religious uses referring to existential or emotional experiences of something we cannot quite put into words (West 2011). The term spirituality is now widely used in many educational, health and therapeutic contexts including early years education (Goodliff 2013); nursing (RCN 2015); psychiatry and mental health (Cooke, Powell \& Sims 2009; Cooke 2013); psychology (Begum 2012; Miller 2012); psychoanalysis (Gleig 2012; Hoffman 2011; Porter 2013; Ross 2010); and health (Cobb, Puchlaski, \& Rumbold 2012; West 2012). Although the term 'spirituality' is used in counselling and psychotherapy there is no substantive agreement as to what this means (Nolan \& West 2014). Most writers identify strands or elements that are synthesised into an overall definition (Ross 2010). This adds layers of complexity to any discussion on spirituality with the potential for misunderstanding. In addition, despite this contemporary interest in the UK there is limited quantitative data available (Coyle 2008) to understand what spirituality is as it relates to therapy, counselling and psychotherapy, although there is a steady growth of qualitative research (Cassar 2013; Jenkins 2006; Layzell 2015). The USA is different story where due to higher attendances at places of worship as a normative part of cultural life there has been a long-standing engagement of religion and spirituality in psychology, counselling and psychotherapy, including quantitative and qualitative research (Pargament 2011; Richards \& 
Bergin 1997; Schmidt \& Jordan, 2010). In the light of this context this research set out to answer two questions. Firstly, what working definitions of, or assumptions about spirituality, do therapists adopt in their work? Secondly, what forms of spiritual phenomena do therapists experience in their work?

\section{Methodology}

Therapists, ranging from students in training to experienced practitioners working in a wide variety of contexts: voluntary, public, NHS, pastoral, university, and private practice completed a 44-item questionnaire presented in two parts. Part one consisted of generic information relating to theoretical orientation, area of work, age, and gender. The provision of their name and e-mail address for further contact was optional but would allow the possibility of further research through semi-structured interviews and an appropriate form of qualitative analysis. This led to four questions: identifying a definition of spirituality; the importance of spirituality for the participant's work as a therapist; the importance of spirituality during training; and the importance of spirituality in clinical supervision. Part two consisted of therapists' awareness and the frequency with which the 36 'spiritual' categories itemized were encountered in clinical settings. These categories were drawn from the existing literature and my immersion in that over the last 20 years. Within these 36 categories were three meta-themes of spirituality of the Sacred that connects us with Other/Being/God beyond the self; spirituality of the Senses that connects our inner and outer worlds and holds the two together; and spirituality of the Self that limits any spiritual connection to within the Self, with no need for any external links. Twelve categories of spiritual experience related to each of these meta-themes of spirituality. One hundred and sixty questionnaires were distributed and one hundred and four were completed. This high return rate was obtained through my personal distribution of the questionnaires in contexts where I was doing training or teaching on spirituality, counselling or psychotherapy. Ethical consent for dissemination and publication was obtained and all data anonymised.

\section{Part One Findings}

The six descriptive categories for spirituality were designed to span a-theistic to theistic perspectives. Connecting part one to part two these descriptive definitions cover spirituality of the Senses (definitions $1 \& 2$ ); spirituality of the Sacred (definitions $3 \& 4$ ); and spirituality of the Self (definitions $5 \& 6$ ). The descriptive definitions are: 
1. A belief in an abstract power, Other or Being that influences self and others in general, non-interventionist ways.

2. A range of metaphysical experiences that communicate moments of awe and wonder that transcend normal human experience

3. A specific belief in a divine Being that can be encountered in a direct way leading to spiritual growth or wholeness

4. Adherence to a spiritual or religious belief system with prescribed ideas and practices

5. The unique potential of each person and the qualities of being human provide a dimension of spirit, without reference to external factors

6. A sense of independent self without the desire for any religious or spiritual belief system or experiences.

This was followed by a subsequent question, 'The impact of my personal belief and experiences about spirituality for my work as a therapist are ...' with a Likert scale response ranging from Very Unimportant (1) to Very Important (5).

Contextual information. The gender of the participants were Female 87.5\% and Male 12.5\%. Given the sample size of 104 when results are converted to a percentage figure these can look a little strange as in the case above. As a comparison this is a higher gender split than that found in the membership of BACP (Britain's largest therapeutic body). The significance of the higher proportion of female participants in the research cohort will be discussed later. The age profile of the participants was similar to the age profile of members of BACP

\begin{tabular}{|l|l|}
\hline Age Profile & Participants (\%) \\
\hline $20-29$ & 4 \\
\hline $30-39$ & 13 \\
\hline $40-49$ & 44 \\
\hline $50-59$ & 27 \\
\hline $60+$ & 12 \\
\hline
\end{tabular}

Theoretical orientation Respondents indicated their self-identified theoretical orientation, which is a little different from BACP membership where the largest group are from the humanistic/person-centred traditions. In the case of pastoral counsellors or therapists this indicates an approach that incorporates religion and spirituality as part of their wider 
philosophical and theoretical understanding of what they do. They saw this as primary and coming before specific orientations such as person-centred or psychodynamic.

\begin{tabular}{|l|l|}
\hline Theoretical Orientation & Participants (\%) \\
\hline Integrative & 50 \\
\hline Psychodynamic/Psychoanalytic & 31 \\
\hline Humanistic & 8 \\
\hline Person-Centred & 7 \\
\hline Pastoral & 5 \\
\hline
\end{tabular}

Employment. Participants were asked to indicate their main place of employment. Typically therapists work part-time and in several different contexts. For example the tutors I employ on my psychodynamic training programme work effectively one day a week, and the rest of their working week is spread across working in schools, GP surgeries and in probate practice.

\begin{tabular}{|l|l|}
\hline Employment as Therapist & Participants (\%) \\
\hline In Training & 45 \\
\hline Private Practice & 26 \\
\hline NHS including GP surgery and Chaplaincy & 14 \\
\hline Voluntary & 13 \\
\hline HE/FE & 2 \\
\hline
\end{tabular}

Importance of spirituality. Participants were asked to indicate the impact of personal spiritual beliefs and experiences on their work. Fifty-one percent $51 \%$ viewed personal beliefs as 'important' (4) and 'very important' (5) for their work using a Likert scale of 1-5. The mean figure was 3.6 with a standard deviation of 1.1 .

Descriptive definitions of spirituality. The origins of these descriptive definitions are located in my long-standing immersion in both theology and psychotherapy. I initially trained as a minister of religion (Baptist) with four years full-time theological training followed by two part-times research degrees (M.Phil and Ph.D) on the interface between religion, spirituality, psychoanalysis and psychotherapy. Having taught, spoken and written about religion, the mystical, pastoral counselling, psychodynamic therapy, counselling skills and theory (Ross 1997, 1999, 2003, 2004, 2006, 2008, 2010, 2014) I have engaged with this interface at depth. These descriptive definitions came out of that deep immersion and span faith-based 
spirituality drawn from religious commitment to secular spirituality. Broad, inclusive language was used throughout the research without avoiding the use of specific religious or spiritual terms, actions or practices. I did not wish to reduce what are held to be profound expression to generic terms that rob words and language of meaning. As a minister I once received a complaint that it was 'All this religion that was spoiling Christmas' likewise there is always a danger that the term spirituality can become so generic or anodyne that it loses its capacity to bear meaning .

\begin{tabular}{|l|l|}
\hline $\begin{array}{l}\text { Key-word description of } \\
\text { spirituality }\end{array}$ & Participants (\%) \\
\hline Abstract power & 9 \\
\hline Metaphysical experiences & 17 \\
\hline Divine Being & 45 \\
\hline Belief system & 4 \\
\hline Unique potential & 19 \\
\hline Independent self & 6 \\
\hline
\end{tabular}

These descriptive definitions can then be combined under three meta-themes of spirituality. Categories 1 and 2 are expressions of a spirituality of the Senses. Here meaning and experience engages with a power that evokes awareness of something other but not specifically defined in religious terms. Thus what a person discovers in them and their experiences of the external work are held in a dynamic and creative balance. Categories 3 and 4 can be seen as a spirituality of the Sacred that connects us with Other/Being/God in a divine dimension. This is encapsulated in the active agency of a transcendent being/Other, often expressed through religious concepts, rituals and experiences. Categories 5 and 6 can be seen as a spirituality of the Self, that is found within the self with no reference to any external other or Other.

\begin{tabular}{|l|l|}
\hline Styles of spirituality & Participants (\%) \\
\hline spirituality of the Senses & 25 \\
\hline spirituality of the Self & 49 \\
\hline spirituality of the Sacred & 26 \\
\hline
\end{tabular}


If we take the largest scoring category 'A specific belief in a divine Being that can be encountered in a direct way leading to spiritual growth or wholeness' and this is broken down by the theoretical orientation of the therapists we can see the following pattern.

\begin{tabular}{|l|l|}
\hline Theoretical orientation & Participants (\%) \\
\hline Pastoral counselling & 100 \\
\hline Humanistic & 63 \\
\hline Integrative & 46 \\
\hline Psychodynamic & 42 \\
\hline Person-centred & 14 \\
\hline
\end{tabular}

Given that pastoral counselling is often linked to a faith tradition, even though the sample was very small (5/104), this is the result that could have been predicted. All participants identifying with this orientation had a specific belief in a Divine Being who can be encountered. The word 'pastoral', is taken from the Christian tradition where the metaphor is used of Jesus, the son of God, caring like a shepherd for his sheep. It implies protection, guidance, and care employed on behalf of others. The percentage figure for the humanistic orientation is also high but it is difficult to make any correlation as the sample size is so small (8/104). The results for both integrative (46\%) and psychodynamic (42\%) theoretical orientations are close to the $51 \%$ overall who viewed personal beliefs as 'important' or 'very important'. This figure for an integrative orientation is important as one aspect of an integrative approach is a philosophical commitment to combining a range of different approaches, which offers the opportunity to include spirituality (Miller 2012). For example, in the work of the Institute of Pastoral Counselling there is a desire to combine Christian thinking with therapeutic knowledge and skills leading to professional accreditation. By contrast given the historic critical stance to any form of religion or spirituality by Freud that has subsequently shaped psychoanalysis and much psychotherapy the result of $42 \%$ is high. It may indicate therapy in the UK parallels a growing movement within psychoanalysis in the USA that incorporates other ways of understanding who a person is and how they can be helped drawing from Buddhism and Christianity (Ross 2010). The low figure of $14 \%$ for a person-centred tradition is in line with Rogers's critical stance to religion and spirituality, despite Thorne's work identifying the spiritual dimensions of a person-centred approach (Thorne 2002, 2008, 2012). However the sample size was small and this needs to be taken into account with a larger study required exploring this finding further. 
The most significant finding relates to the low scores associated with the two definitions that form the polarities of the spectrum. The definition 'Adherence to a spiritual or religious belief system with prescribed ideas and practices' best describes orthodox religious believers participating in organised religions yet this was identified by only $4 \%$ of the participants. Similarly the definition 'A sense of independent self without the desire for any religious or spiritual belief system or experiences' best describes an atheistic or non-believing position but this was adopted by only $6 \%$ of the participants. Clearly therapists are less willing to identify with explicit belief systems, theistic or non-theistic, either an absolute belief in God or the Self. This finding supports sociologist of religion Grace Davie's thesis that contemporary British religious culture is characterized by 'believing without belonging' (1994) and Heelas and Woodhead's thesis that 'religion is giving way to spirituality' (Heelas \& Woodhead 2005).

\section{Part Two Findings}

Participants completed a 36 item identifying categories of spiritual experience using a Likert scale: $1=$ Never; $2=$ Rarely; $3=$ Sometimes; $4=$ Often; and $5=$ Very Often. Within these 36 categories there were three spheres of spirituality represented: a spirituality of Self; a spirituality of Sacred Other; and a spirituality of Meaning and Experience. These were scattered randomly across the 36 categories. The respondents rated seven categories of spiritual phenomena as occurring 'often' or 'very often' and five categories 'rarely' or 'never'.

\begin{tabular}{|l|l|}
\hline Spiritual Experience & $\begin{array}{l}\text { Participants 'Often' \& 'Very Often' (highest } \\
\text { scoring \%) }\end{array}$ \\
\hline Sensitivity to the other person & 96 \\
\hline Warmth of personhood & 86 \\
\hline Humility in the face of life events & 81 \\
\hline The presence of hope & 81 \\
\hline Love & 75 \\
\hline Unspoken connection with a client & 71 \\
\hline Searching for meaning & 67 \\
\hline & $\begin{array}{l}\text { Participants 'Never' \& 'Rarely' (highest } \\
\text { scoring \%) }\end{array}$ \\
\hline
\end{tabular}




\begin{tabular}{|l|l|}
\hline Use of a sacred text & 79 \\
\hline A specific religious system & 70 \\
\hline A destined path & 65 \\
\hline Encounters with a spiritual entity & 65 \\
\hline A desire to pray & 63 \\
\hline
\end{tabular}

What does this tell us about spirituality in therapy?

Spirituality is important and for many there is a background belief in God/Being/Other (Part One $49 \%$ ) but this is not translated into expression in the therapeutic space through the use of religious traditions, practices or rituals. This is clearly demonstrated in the five highest scoring categories that relate to 'Rarely' or 'Never' These categories were those adopting clear religious terminology: destined path, prayer etc. not just terms related to the Christian tradition. Yet we do know therapists pray (Gubi 2008) and this is seen to be an important part of their therapeutic work.

The highest rated category was 'sensitivity to the other person' and by inference this implies openness to the whole person, including their spirituality. These high scoring categories can be the most profound aspects of being human that therapist aspire to. This research did not however explore whether the source of such human aspirations are found in emerging out of a set or religious or spiritual beliefs? Clearly the general belief in there being a God (however defined), orientates each therapist to being a particular kind of person that embraces such ideals. In terms of these highest scoring categories there is an emphasis on a spirituality of the Self that operates within self-defined limits.

The mean score for the meta-themes of spirituality categories were identified and combined to form one composite figure based on the theoretical orientation of the therapist.

\begin{tabular}{|l|l|l|l|}
\hline & $\begin{array}{l}\text { Spirituality of the } \\
\text { Self }\end{array}$ & $\begin{array}{l}\text { Spirituality of the } \\
\text { Sacred }\end{array}$ & $\begin{array}{l}\text { Spirituality of the } \\
\text { Senses }\end{array}$ \\
\hline Pastoral & 3.62 & 3.17 & 3.36 \\
\hline $\begin{array}{l}\text { Humanistic/Person- } \\
\text { Centred }\end{array}$ & 3.42 & 2.28 & 3.58 \\
\hline Integrative & 3.32 & 2.46 & 3.74 \\
\hline Psychodynamic & 3.27 & 2.32 & 2.86 \\
\hline
\end{tabular}


The most important category for pastoral counsellors is intriguingly a spirituality of the Self, followed by a spirituality of the Senses, then by a spirituality of the Sacred. However this group were the highest scoring in terms of the Sacred. Humanistic/Person-Centred therapists and trainees were fairly equally balanced between a spirituality of the Senses and the Self and obtained the lowest score for a spirituality of the Sacred. Integrative therapists and trainees were the highest scoring for a spirituality of the Senses. Psychodynamic therapists and trainees were low scoring for the spirituality of the Sacred and the Senses, opting primarily for a spirituality of the Self.

One research outcome that is easy to overlook is the fact that approximately $90 \%$ of the respondents were female, which in itself is unsurprising as the vast majority of therapists are women (for BACP members it is $78 \%$ ). This raises two crucial reflexive questions, 'Why is this the case for the therapy professions?' and 'Can this research more accurately be viewed as an expression of female spirituality in therapy?' The first question is beyond the scope of this research however the notion of a distinctly female spirituality and faith development has evolved through the emergence of Christian feminism in the last twenty years (Slee, 2003). Slee's research has identified different patterns of faith development for women (2004), and this links to different patterns of spiritual expressions, styles, practices, and rituals (Slee, Porter \& Philips 2013). There are expressions of male-spirituality develop by Rohr (1996, 2004a, 2004b; Rohr \& Martos, 2005) but insufficient research has yet been done and none directly related to male spirituality and therapy.

\section{Limitations}

The words used to describe spiritual categories or phenomena were not always understood by respondents and were open to various interpretations. The desire to use 'open' language to enhance inclusion also raises the possibility and complication of alternative meanings. Some completed questionnaires had a small amount of missing data and in order to deal with this the data was assigned the mean score for that category. In one case the questionnaires were completed by fifteen students on a psychodynamic course where I was the Director and so issues of transference may have been at work.

\section{Conclusions}


There are few qualitative studies on spirituality (Coyle 2008), and those that do exist largely originate from the USA (Pargament 2011). This research offers insights into a range of phenomenon encountered in therapy viewed as having spiritual dimensions. The increasing cultural interest in spirituality suggests this is something therapists need to be aware of, and prepared for, in their work. This research spans the emergence and rapid growth of Mindfulness in the UK and explains why Mindfulness has become so powerful. By drawing and Buddhist and Christian origins through meditation and prayer it gives place to a spirituality of the Self and a spirituality of the Sacred but allows the participants to pitch this at whatever level is appropriate which they experience in their real world through a spirituality of the Senses.

The pattern that emerges is that the therapeutic world parallels what is happening in the wider culture within the UK where there appears to be a generic belief in an external Being, but little commitment to religious traditions. Religion it appears is being replaced by spirituality. In this research there was no one dominant form of spirituality and the therapeutic enterprise involves all three expressions as identified: spiritualities of the Self, the Sacred and the Senses. How these engage with one another is in part influenced by the life experience the individual therapist brings in terms of their personal experience and the philosophical influence inherent in the different theoretical traditions that maximize or minimize the place for religious and spiritual experiences. The nature of spirituality is under-researched in the UK and requires more in-depth analysis of therapist and client experiences, qualitatively and quantitatively. This paper offers a starting point and further research could examine whether there are distinctive gender-based forms of spirituality.

\section{References}

Begum, N. (2012). Trainee clinical psychologists talking about religion and spirituality in their work (Unpublished D.Clin. Psychol.). University of East London.

Candy, B., Jones, L., Varagunam, M., Speck, P., Tookman, A., \& King, M. (2012). Spiritual and religious interventions for well-being of adults in the terminal phase of disease (Cochrane Review). Retrieved from http://onlinelibrary.wiley.com/doi/10.1002/14651858.CD007544.pub2/abstract Cassar, S. (2013) The impact of Psychotherapists' spiritual practice, beliefs and values on their clinical work (Unpublished Psych. D.). Middlesex University.

Cobb, M., Puchlaski, C., \& Rumbold, B. (Eds.). (2012). Oxford textbook of spirituality in healthcare. Oxford: OUP.

Cook, C. C. H. (Ed.). (2013). Spirituality, theology and mental health: Multidisciplinary perspectives. London: SCM Press. 
Cook, C. C. H., Powell, A., \& Sims, A. (Eds.). (2009). Spirituality and psychiatry. London: Royal College of Psychiatrists Press.

Coyle, A. (2008). Qualitative methods and 'the (partly) ineffable' in psychological research on religion and spirituality. Qualitative Research in Psychology, 5, 56-67.

doi:10.1080/14780880701863583

Davie, G. (1994). Religion in Britain since 1945: Believing without belonging. Oxford: Blackwell.

Gleig, A. (2012). The return of the repressed: Psychoanalysis as spirituality. Implicit Religion 15, 209-224. doi:10.1558/imre.v15.i2.11197

Goodliff, G. (2013). Young children's expressions of spirituality: An ethnographic case study (Unpublished EdD.), The Open University.

Gubi, P. (2008). Prayer in counselling and psychotherapy: Exploring a hidden meaningful dimension. London: Jessica Kingsley.

Heelas, P., Woodhead, L., Seel, B., Szerszynski, B. \& Tusting, K. (2005). The spirituality revolution: Why religion is giving way to spirituality. Oxford: Blackwell.

Hoffman, M. (2011). Toward mutual recognition: Relational psychoanalysis and the Christian narrative. New York: Routledge.

Jenkins, C., (2006). A voice denied, clients' experience of the exclusion of spirituality in counselling and psychotherapy (Unpublished $\mathrm{PhD}$ Thesis). University of Manchester.

Layzell, R. (2015). And it was night. Psychological and theological perspectives on the pastoral accompaniment of adults experiencing psycho-spiritual extremity (Unpublished D.PT. thesis). University of Chester.

Miller, L. (Ed.). (2012). The Oxford handbook of psychology and spirituality. Oxford:

OUP.

Nolan, G. \& West, W. (Eds.).(2014). Exploring therapy, culture and

spirituality. Developing therapeutic practice. Basingstoke: Palgrave Macmillan.

Pargament, K. (2011). Spiritually integrated psychotherapy (2 ${ }^{\text {nd }}$ ed.). New York: Guilford Press.

Porter, K. (2013). Can there be a spiritual psychoanalysis? Psychoanalytic Perspectives, 10, 235-269. doi:10.1080/00330124.2013.826952

Richards, S. \& Bergin, A. (1997). A spiritual strategy for counseling and psychotherapy. Washington, DC: American Psychological Association.

Rohr, R. (1996). Wild man's journey: Reflections on male spirituality (Revised ed.).

Cincinnati OH: St Anthony Messenger Press.

Rohr, R. (2004a). Adam's return: The five promises of male initiation. Chestnut Ridge, NY:

Crossroad Publishing.

Rohr, R. (2004b). Soul brothers: Men in the Bible speak to men today. Maryknoll, NY.

Orbis Books.

Rohr, R. \& Martos, J. (2005). From wild man to wise man: Reflections on male

spirituality. Cincinnati OH: St Anthony Messenger Press.

Ross, A. (1997) Evangelicals in exile - Wrestling with theology and the unconscious. London: DLT.

Ross, A. (1999). The place of religious tradition in pastoral counselling. In G. Lynch (Ed.), Clinical counselling in pastoral settings (pp. 37-50). London: Routledge.

Ross, A. (2003). Counselling skills for church and faith community workers. Maidenhead: Open University Press.

Ross, A. (2004). Pastoral Counselling. In M. Reid (Ed.), Counselling in different settings The reality of practice (pp. 193-206). Basingstoke: Palgrave MacMillan. 
Ross, A. (2006). Psychodynamic counselling, religion and spirituality. In S. Wheeler (Ed.), Difference and diversity in counselling - Contemporary psychodynamic practice (pp. 171183). Basingstoke: Palgrave Macmillan.

Ross, A. (2008) The stag and the doe: Archetypes of the Spirit. In S. Burns, M. Jaegassar \& N. Slee (Eds.), The Edge of God (pp. 217-226) London: SCM Press.

Ross, A. (2010). Sacred psychoanalysis (Unpublished PhD thesis). University of Birmingham.

Ross, A. (2014). A story of falling. Therapy Today, 25 (8), 22-25.

Royal College of Nursing. (2015). spirituality in nursing care: online resources. Retrieved January 23, 2015, from

http://www2rcn.org.uk_data/assets/pdf_file/0008/395864/Spirituality_online resource_Final. $\underline{\mathrm{pdf}}$

Schmidt, W. \& Jordan, M. (Eds.). (2010). The spiritual horizon of psychotherapy. London: Routledge.

Slee, N. (2003). Faith and feminism: An introduction to Christian feminist theology. London: DLT.

Slee, N. (2004). Women's faith development: Patterns and processes. Farnham: Ashgate.

Slee, N., Porter, F. \& Phillips, A. (Eds.). (2013). The faith lives of women and girls.

Qualitative research perspectives. Farnham: Ashgate.

Thorne, B. (2002). The mystical power of Person-centred therapy: Hope beyond despair.

London: Whurr.

Thorne, B. (2008). Person-centred counselling: Therapeutic and spiritual dimensions.

London: Whurr.

Thorne, B. (2012). Counselling and spiritual accompaniment: Bridging faith and Personcentred therapy. Oxford: Wiley-Blackwell.

West, W. (Ed.) (2011). Exploring therapy, spirituality and healing. Basingstoke: Palgrave Macmillian.

West, W. (2012) Counselling. In M. Cobb, C. Puchalski, \& B. Rumbold (Eds.), Spirituality and health (pp. 279-284). Oxford: OUP. 